\title{
C-Cl (Carbon-Chlorine)
}

\section{H. Okamoto}

The C-Cl phase diagram was unknown in [Massalski2].

Figure 1 shows a partial $\mathrm{C}-\mathrm{Cl}$ phase diagram between $\mathrm{CCl}_{4}$ and $\mathrm{Cl}$ determined by [1975 Aba] by means of thermal analysis. The existence of $\mathrm{C}_{7} \mathrm{Cl}_{5}, \mathrm{C}_{5} \mathrm{Cl}_{4}, \mathrm{C}_{7} \mathrm{Cl}_{8}, \mathrm{C}_{4} \mathrm{Cl}_{5}$, and $\mathrm{CCl}_{3}$ is reported in [2007Vil] outside the composition range shown in Fig. 1.

Table 1 shows $\mathrm{C}-\mathrm{Cl}$ crystal structure data. In addition to the two forms of $\mathrm{CCl}_{4}$ given in Table 1, [1975Aba] observed a metastable fcc form of $\mathrm{CCl}_{4}$ forming below $-27.1^{\circ} \mathrm{C}$.

\section{References}

1975Aba: M. Abassalti and M. Michaud, Chlorine-Carbon Tetrachloride System. Polymorphism of Tetrachloride, Rev. Chim. Min., 1975, 12(2), p 134-138, in French

2007Vil: P. Villars and K. Cenzual, Pearson's Crystal Data $C D-R O M$, ASM International, OH, 2007

Table 1 C-Cl crystal structure data

\begin{tabular}{|c|c|c|c|c|c|}
\hline Phase & Composition, at.\% Cl & Pearson symbol & Space group & Strukturbericht designation & Prototype \\
\hline $\mathrm{\beta CCl}_{4}$ & 80 & $o^{* *}$ & $\cdots$ & $\cdots$ & $\cdots$ \\
\hline$\alpha \mathrm{CCl}_{4}$ & 80 & $m C 160$ & $C 12 / c 1$ & $\cdots$ & $\mathrm{CBr}_{4}$ \\
\hline$(\mathrm{Cl})$ & 100 & $o C 8$ & Cmca & $A 14$ & I \\
\hline
\end{tabular}

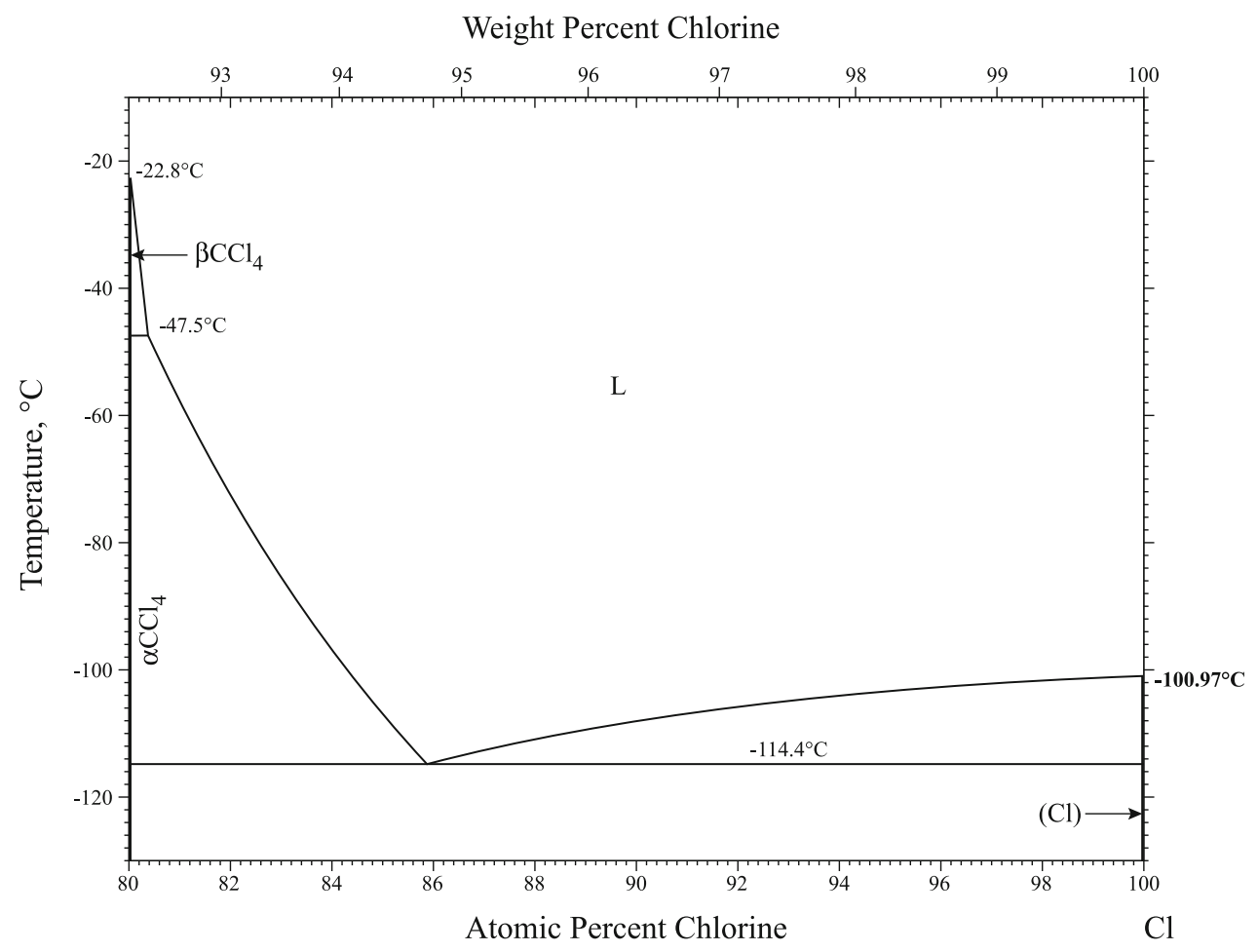

Fig. $1 \mathrm{C}-\mathrm{Cl}$ phase diagram 